\title{
RT-SHIV, an infectious CCR5-tropic chimeric virus suitable for evaluating HIV reverse transcriptase inhibitors in macaque models Yonghou Jiang1, Baoping Tian ${ }^{1}$, Mohammed Saifuddin'², Michael B Agy ${ }^{1}$, Peter Emau1 ${ }^{1}$ J Scott Cairns ${ }^{3}$ and Che-Chung Tsai*1
}

\author{
Address: ${ }^{1}$ Washington National Primate Research Center, University of Washington, Box 357330 Health Sciences Building, Seattle, Washington \\ 98195, USA, ${ }^{2}$ CONRAD, Eastern Virginia Medical School, Arlington, Virginia 22209, USA and ${ }^{3}$ Fifth Opus Consulting, LLC Mercer Island, \\ Washington 98040, USA \\ Email: Yonghou Jiang - yhjiang@wanprc.org; Baoping Tian - baoping@wanprc.org; Mohammed Saifuddin - msaifuddin@conrad.org; \\ Michael B Agy - magy@u.washington.edu; Peter Emau - pemau@snblusa.com; J Scott Cairns - scottcairns@comcast.net; Che- \\ Chung Tsai* - cctsai@u.washington.edu \\ * Corresponding author
}

Published: 5 November 2009

AIDS Research and Therapy 2009, 6:23 doi:10.1186/1742-6405-6-23
Received: 4 July 2009

Accepted: 5 November 2009

This article is available from: http://www.aidsrestherapy.com/content/6/I/23

(C) 2009 jiang et al; licensee BioMed Central Ltd.

This is an Open Access article distributed under the terms of the Creative Commons Attribution License (http://creativecommons.org/licenses/by/2.0), which permits unrestricted use, distribution, and reproduction in any medium, provided the original work is properly cited.

\begin{abstract}
Background: Non-nucleoside reverse transcriptase inhibitors (NNRTIs) are an important category of drugs for both chemotherapy and prevention of human immunodeficiency virus type I (HIV-I) infection. However, current non-human primate (NHP) models utilizing simian immunodeficiency virus (SIV) or commonly used chimeric SHIV (SIV expressing HIV-I envelope) are inadequate due to the insensitivity to NNRTIs. To develop a NHP model for evaluation of NNRTI compounds, we characterized a RT-SHIV virus that was assembled by replacing the $\mathrm{SIV}_{\text {mac239 }}$ reverse transcriptase (RT) with that of HIV-IHXB2. Since RT-SHIV exhibited in vitro characteristics of high infectivity, CCR5-usage, and sensitivity to HIV-I specific NNRTIs, this virus was thought to be suitable for mucosal transmission and then was used to carry out a vaginal transmission study in pigtail macaques (Macaca nemestrina).
\end{abstract}

Results: RT-SHIV exhibited in vitro characteristics of an infectious CCR5-tropic chimeric virus. This virus was not only highly sensitive to HIV-I RT specific NNRTIs; its replication was also inhibited by a variety of NRTIs and protease inhibitors. For in vivo vaginal transmission studies, macaques were either pretreated with a single dose of DMPA (depot medroxyprogesterone acetate) or left untreated before intravaginal inoculation with 500 or I,000 $\mathrm{TCID}_{50}$ of RT-SHIV. All macaques became systemically infected by 2 or 3 weeks post-inoculation exhibiting persistent high viremia, marked $C D 4^{+} T$ cell depletion, and antiviral antibody response. DMPA-pretreated macaques showed a higher mean plasma viral load after the acute infection stage, highly variable antiviral antibody response, and a higher incidence of AIDS-like disease as compared with macaques without DMPA pretreatment.

Conclusion: This chimeric RT-SHIV has exhibited productive replication in both macaque and human PBMCs, predominantly CCR5-coreceptor usage for viral entry, and sensitivity to NNRTIs as well as other anti-HIV compounds. This study demonstrates rapid systemic infection in macaques following intravaginal exposure to RT-SHIV. This RT-SHIV/macaque model could be useful for evaluation of NNRTI-based therapies, microbicides, or other preventive strategies. 


\section{Background}

Heterosexual contact is the predominant route of virus transmission for the HIV epidemics especially in the developing countries worldwide, where women are most vulnerable [1]. The pandemic spread of HIV/AIDS through sexual contact and the slow progress towards an effective vaccine have prompted the search for effective vaginal and rectal microbicides to help mitigate HIV mucosal transmission [2-10]. Various agents have been investigated as topical anti-HIV microbicides including nonnucleoside reverse transcriptase inhibitors (NNRTIs) $[2,3,5,11-23]$. For an effective preclinical evaluation of these agents, validated animal models are urgently needed. Ideally, the challenge viruses for these models should mimic HIV mucosal transmission predominantly using CCR5 coreceptor, express HIV-1 genes such as RT that are appropriate as therapeutic targets, and induce rapid and readily detectable systemic infection that progress to AIDS-like illness.

NNRTI compounds with high binding affinity for RT are potent inhibitors of HIV-1 replication. However, due to the specific reactive-site requirements of NNRTI, these compounds only inhibit the RT of HIV-1, but not SIV or HIV-2. Thus, while SIV and HIV-2 are well suited to study lentivirus infection and pathogenesis in Asian macaques, they cannot be used to evaluate virus control by HIV-1 specific NNRTI compounds. Early attempts to overcome subtle differences between HIV and SIV while allowing for productive macaque infections resulted in development of several chimeric SHIV strains. The first SHIV construction sought incorporation of HIV-1 env into SIV and was used to challenge macaques immunized with HIV-1 envbased candidate vaccines. After that a number of RT-SHIV strains were constructed to evaluate the activity of HIVspecific NNRTIs both in vitro and in macaques [24-29]. Consequently, several macaque models were developed by using different RT-SHIVs [23-26,29-36]. Since most of these RT-SHIV/macaque models were designed to evaluate NNRTIs as therapies, the preferred infection route was intravenous injection. However, recently, mucosal transmission of RT-SHIV have been reported by two laboratories [34,35] in which all rhesus macaques had been pretreated with DMPA (Depo Provera ${ }^{\circledR}$ ) before intravaginal viral exposure. It is known that prior administration of DMPA enhances mucosal viral transmission by thinning of the vaginal epithelium [37] and also possibly by suppression of antiviral immune response [38].

Clearly, a more physiologically relevant RT-SHIV/ macaque model for mucosal transmission will help expedite evaluation of anti-HIV topical microbicides. We have serially passaged an RT-SHIV virus stock obtained from Louis Alexander [28] in different cell types including human and macaque PBMCs before generating a large virus stock in CEMx174 cells for in vitro and in vivo characterization. The in vitro studies show that the new virus stock was highly replicative in both human and macaque cells, predominantly CCR5-tropic and highly sensitive to NNRTIs. This RT-SHIV stock was then used to infect pigtail macaques by intravaginal inoculation. In this report we have demonstrated an efficient transmission of this RT-SHIV through single intravaginal exposure in both DMPA-treated or untreated macaques, and compared the virus transmission efficiency, levels of plasma viremia, clinical outcome and antiviral antibody response between the two groups. Consequently, we have established a suitable non-DMPA RT-SHIV model in pigtail macaques for efficacy evaluation of anti-HIV drugs especially NNRTIbased topical microbicides.

\section{Results \\ In vitro replicability of $R T$-SHIV}

As shown in Figure 1A, RT-SHIV replicated rapidly to high levels in PBMC cultures from both humans (huPBMC) and macaques (Macaca nemestrina, mnePBMC and M. fascicularis, mfaPBMC). RT-SHIV replication ability in human CD4+Tcell lines is shown in Figure 1B. This virus replicated efficiently to high levels in MT-4, CEMx174 and PM1, to low levels in MOLT4CCR5 and poorly in MT-2 cells. The in vitro specificity of CCR5 coreceptor usage by RT-SHIV is shown in Figure 1C. In vitro replication kinetics of RT-SHIV, SIV mac239 $_{3}$ and HIV- $1_{\text {Lai }}$ in CEMx174 cells are shown in Figure 2. Three viruses exhibited similar replication kinetics as evidenced by the production of viral core antigen in the culture supernatants. Together, these results indicate that RT-SHIV revealed the characteristics of a highly infectious and rapid replicating CCR5-tropic virus.

\section{Coreceptor usage of RT-SHIV for the entry of target cells} The chemokine receptors CCR5 and CXCR4 are the two main coreceptors essential for HIV, SHIV and SIV entry. To determine chemokine receptor use by RT-SHIV, we studied the ability of five different human $\mathrm{CD} 4{ }^{+} \mathrm{T}$ cell lines known to express one or more coreceptors on the cell surface [MT-2 (CXCR4), MT-4 (CXCR4/other), MOLT4CCR5 (CCR5), PM1 (CCR5), and CEM x174 (CXCR4/CCR5/ other)] to support replication of this virus. As shown in Figure $1 \mathrm{~B}$, the RT-SHIV replicated to a high level in the CCR5-expressing CEMx174 and PM1 cells, and unexpectedly also in MT4 cells that do not express CCR5 but CXCR4 and possibly other receptors. Interestingly, RTSHIV did not replicate well in MOLT4 cells that express CCR5, and did not grow at all in CXCR4-expressing MT-2 cells. Furthermore, the level of virus replication was directly correlated with the level of syncytium induction (SI) in CCR5-expressing CEMx174 and PM1 cells (syncytial data not shown); however, there was no SI in CXCR4expressing MT4 cells in spite of high virus replication, and in contrast, relatively high level of SI activity observed in 

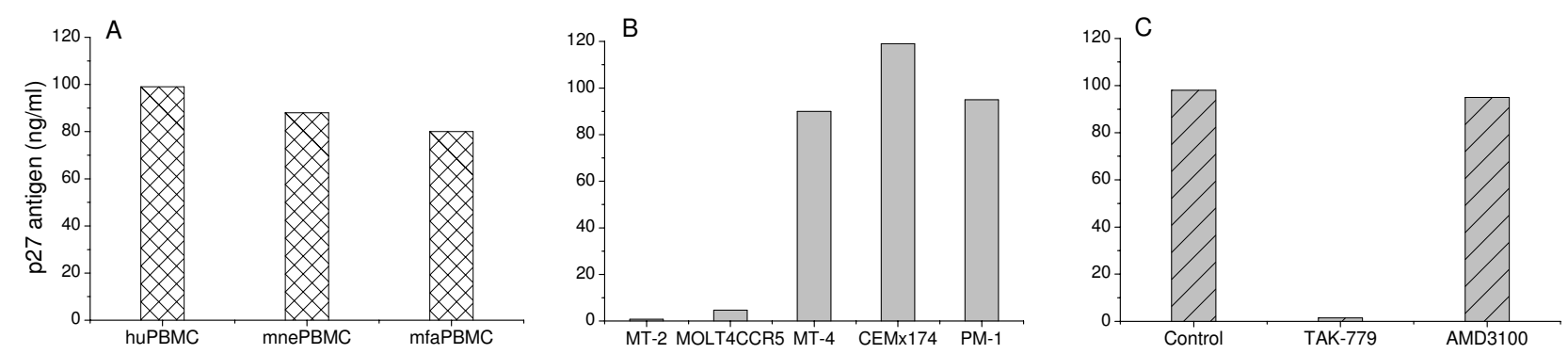

\section{Figure I}

In vitro characterization of RT-SHIV. Replication of RT-SHIV in cultures of PBMCs from humans (huPBMC) and macaques (Macaca nemestrina, mnePBMC; Macaca fascicularis, mfaPBMC) is shown in panel A. The coreceptor tropism of RT-SHIV is shown in five different human CD4 ${ }^{+} T$ cell lines in panel $B$. The specific coreceptor usage by RT-SHIV is shown in panel $C$ where human PBMC cultures were treated with or without coreceptor antagonist TAK-779 or AMD-3100 before incubating with RT-SHIV. Relative virus replication levels (core antigen SIV p27) measured in the culture supernatants after 7 days post incubation, are shown at the left of the panels. Values shown here are representative of three independent experiments.

MOLT4 cells with a low level of virus replication. There was no p27 antigen production or SI activity in CXCR4expressing MT-2 cells (Figure $1 \mathrm{~B}$, data not shown). These data may suggest that RT-SHIV predominantly use CCR5 coreceptor for target cell entry; nevertheless other unknown receptors may also be involved for viral entry and SI activity.

Additional evidence of CCR5 coreceptor usage by RTSHIV was shown in Figure 1C where human PBMC cultures were treated with or without coreceptor antagonists TAK-779 or AMD-3100 before exposing to virus. RT-SHIV replication was markedly inhibited ( $\geq 91 \%)$ by TAK-779 (CCR5 antagonist, $10 \mu \mathrm{M}$ ) [39] but not by a concentration of AMD-3100 (CXCR4 antagonist, 1,000 ng/ml) [40] that strongly inhibited CXCR4-tropic HIV-1 ${ }_{\text {Lai }}$ [41]. Similar results were also obtained with macaque PBMCs (data not shown). Together, these data indicate that our RTSHIV favors the CCR5 coreceptor mediated entry for replication in the target cells.

\section{Sensitivity of RT-SHIV and other lentiviruses to NNRTIs}

Various concentrations of three different NNRTIs (efavirenz, nevirapine and UC781) were used to assess their inhibitory effects against the replication of HIV-1, RTSHIV, SIV mac239, $_{\text {SIV }}$ mac251, and SHIV $_{89.6 P}$ in PBMC and different human CD4+cell lines. As shown in Table 1, the 50 percent effective concentration $\left(\mathrm{EC}_{50}\right)$ of each compound against specific virus and their 50 percent cytotoxicity concentration $\left(\mathrm{CC}_{50}\right)$ (tested in uninfected cell cultures) calculated by linear regression analysis were determined in specific target cells. The replication of HIV-1 and RT-SHIV was markedly inhibited by all three NNRTIs, while $\mathrm{SIV}_{\text {mac239 }}, \mathrm{SIV}_{\text {mac251 }}$, and SHIV $_{89.6 \mathrm{P}}$ were either not inhibited at all or inhibited to a much lesser extent. These results confirmed that RT-SHIV retained the HIV-1 RT encoding region and remained sensitive to NNRTIs.

\section{Inhibitory effects of other anti-HIV compounds on RT- SHIV replication}

In addition to NNRTIs, we also measured the inhibitory effects of a variety of other anti-HIV compounds on RTSHIV replication in vitro. CEMx174 cells were incubated with RT-SHIV in the presence or absence of various concentrations of each anti-HIV compound. The $\mathrm{CC}_{50}$ and $\mathrm{EC}_{50}$ were determined as described above. The selectivity index (SI), the ratio of $\mathrm{CC}_{50}$ to $\mathrm{EC}_{50}$ was also determined. As shown in Table 1 and Table 2, RT-SHIV was markedly inhibited by all three NNRTIs (UC781, efavirenz, and nevirapine), and also by a number of NRTIs (AZT and D4T), and protease inhibitors (PIs: indinavir and saquinavir). The antiviral effect was less pronounced with 3TC, FTC, tenofovir, and ritonavir; nevertheless, these in vitro efficacy data indicate that RT-SHIV is sensitive not only to NNRTIs but also to NRTIs and PIs. Thus, the RT-SHIV/ macaque model could be suitable for efficacy evaluation of microbicides and a variety of anti-HIV drugs (i.e., NNRTIs, NRTIs, or PIs).

\section{Systemic infection after vaginal RT-SHIV transmission in macaques}

To establish mucosal transmission of RT-SHIV, a group of four pigtail macaques were pretreated with or without DMPA (depot medroxyprogesterone acetate, Depo Provera $^{\circledR}$ ) for 30 days before inoculating with a single dose of 500 or 1,000 TCID $_{50}$ of virus. Regardless of DMPA pretreatment or the viral inoculum dose (500 or 1,000 $\left.\mathrm{TCID}_{50}\right)$, all macaques became systemically infected within two weeks of intravaginal inoculation of RT-SHIV as determined by the presence of both high level viral 


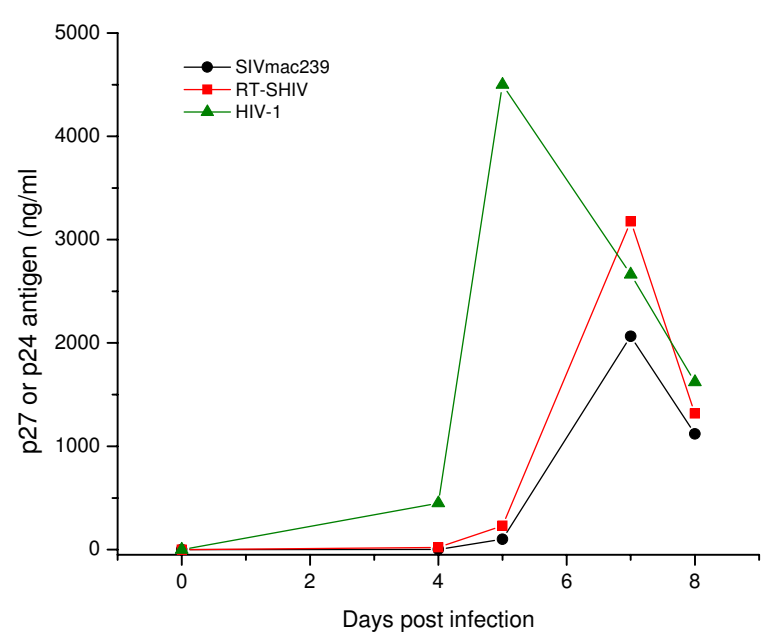

Figure 2

Replication kinetics of RT-SHIV, SIV, and HIV-I. Human CEMxI74 cells were infected with RT-SHIV, SIV $_{\text {mac239 }}$ and HIV-I Lai at doses equivalent to multiplicity of infection of 0.0I. SIV p27 or HIV-I p24 antigen levels (shown on the left) were measured in culture supernatants to monitor viral replication. Each time point represents the average of duplicate cultures and data shown here are the mean of three independent experiments.

RNA in plasma (Figures $3 \mathrm{~A}, \mathrm{~B}, \mathrm{C}$ ) and proviral DNA in PBMCs (data not shown). Both DMPA-treated and nontreated macaques showed a peak plasma viremia greater than $10^{6}$ copies/ml ( 5 of 8 macaques had a peak viremia above $10^{7} \mathrm{copies} / \mathrm{ml}$ ) during the acute stage of infection (week 2-4 post inoculation, pi) (Figure 3). However, the set point of virus load at post acute stage (week 8-12 pi) and particularly at the late stage (week 16-20 pi) was significantly higher in DMPA-treated macaques than in nonDMPA macaques ( $\mathrm{p}<0.05$, independent $t$ tests).

\section{Changes of CD4'T cell and B cell numbers in RT-SHIV infected macaques}

All RT-SHIV infected macaques showed a significant $\mathrm{CD} 4{ }^{+} \mathrm{T}$ cell depletion in peripheral blood (Figure 4A,B). The decline of $\mathrm{CD}^{+} \mathrm{T}$ cells at the acute stage of infection (week 2-4 pi) was slightly more pronounce in non-DMPA macaques than the DMPA-treated macaques. As shown in Figure 4C and 4D, both DMPA-treated and untreated macaques also showed a sharp decrease of $B$ cells in peripheral blood during the initial phase of viral infection (week 2-3 pi). Interestingly, three of four DMPA-treated macaques showed a gradual decline of $\mathrm{B}$ cells until the end of the study (week 24 pi) but one macaque (04103) showed a large increase in B cells at week 4 pi and then a gradual decline until week 24 pi. In contrast, three of four non-DMPA macaques showed a continuous increase of $\mathrm{B}$ cells until week 24 pi, and one macaque (99151) in this group maintained a moderately low level $\mathrm{B}$ cell during week 12-24 pi following a slight increase at week 4 pi. The overall lower B cell numbers in DMPA macaques compared to non-DMPA group imply that DMPA treatment may have affected the humoral antiviral immune response.

Antiviral antibody response in RT-SHIV infected macaques Antiviral antibodies (Abs) were detected in all RT-SHIV infected macaques at week 4 pi (Figure 5). DMPA-treated macaques showed a significant variation in their $A b$ response. Three macaques (04103, 04093 and 04099) showed greatly fluctuating levels of $\mathrm{Ab}$ while macaque 04107 showed gradual increase in Ab up to week 16 pi before decreasing at later time points. In contrast, nonDMPA macaques showed an uniform high level Ab response which increased gradually until peaked between week 12-16 pi, and was maintained thereafter except the macaque A99296 that peaked at week 20 before plateauing.

\section{Clinical features of RT-SHIV infected macaques}

The clinical outcomes were more severe in the DMPAtreated macaques than non-DMPA macaques. Three of four macaques in DMPA group were euthanized due to AIDS-like disease (severe CD4 ${ }^{+} \mathrm{T}$ cell depletion, weight loss, recurrent diarrhea) by week 24 pi. Positive proviral DNA and recoverable infectious virus was detected in blood, lymphoid and reproductive tissues collected at necropsy in these three macaques. The fourth macaque (04107) with persistent viremia and severe CD4+T cell depletion also showed AIDS-like disease and was eutha-

Table I: In vitro efficacy of NNRTIs against RT-SHIV and other lentiviruses

\begin{tabular}{|c|c|c|c|c|c|c|}
\hline \multirow[t]{2}{*}{ NNRTIs } & \multirow[t]{2}{*}{$\mathrm{CC}_{50}(\mu \mathrm{M})$} & \multicolumn{5}{|c|}{$E C_{50}(\mu M)$} \\
\hline & & HIV-I* & RT-SHIV & $\mathbf{S I V}_{\text {mac239 }}$ & SIV mac25I $_{1}$ & $\mathrm{SHIV}_{89.6 \mathrm{P}}$ \\
\hline Efavirenz & $3 \sim 45$ & $<0.001$ & 0.003 & $>5$ & $>5$ & $>5$ \\
\hline Nevirapine & $84 \sim 100$ & 0.028 & 0.06 & $>100$ & $>100$ & $>100$ \\
\hline UC78I & $51 \sim 66$ & $<0.005$ & 0.003 & $>50$ & $>10$ & $>20$ \\
\hline
\end{tabular}

$\mathrm{CC}_{50}: 50 \%$ cytotoxic concentration; $\mathrm{EC}_{50}: 50 \%$ effective concentration.

*NNRTIs showed a strong inhibitory activity to both $\mathrm{HIV}-\mathrm{I}_{\mathrm{Lai}}$ and $\mathrm{HIV}-\mathrm{I}_{\mathrm{BaL}}$. 
Table 2: Inhibition of RT-SHIV replication by antiretroviral compounds

\begin{tabular}{|c|c|c|c|c|}
\hline Drugs Category & Anti-HIV drugs & $\begin{array}{l}\mathrm{EC}_{50} \\
(\mu \mathrm{M})\end{array}$ & $\begin{array}{l}\mathbf{C C}_{50} \\
(\mu \mathrm{M})\end{array}$ & Selectivity index(SI) \\
\hline \multirow{3}{*}{ NNRTIs } & Efavirenz & $0.002 \pm 0.001$ & $35.72 \pm 25.45$ & 17860 \\
\hline & Nevirapine & $0.06 \pm 0.01$ & $>100$ & $>1667$ \\
\hline & UC78I & $0.003 \pm 0.002$ & $59.22 \pm 6.56$ & 19740 \\
\hline \multirow[t]{5}{*}{ NRTIs } & Zldovudine (AZT) & $0.01 \pm 0.01$ & $>100$ & $>10000$ \\
\hline & Lamivudine (3TC) & $0.43 \pm 0.13$ & $>100$ & $>233$ \\
\hline & Stavudine (D4T) & $0.01 \pm 0.01$ & $66.48 \pm 34.84$ & 6648 \\
\hline & Emtricitabine (FTC) & $0.1 \pm 0.1$ & $>100$ & $>1000$ \\
\hline & Tenofovir & $0.82 \pm 0.62$ & $>100$ & $>122$ \\
\hline \multirow[t]{3}{*}{ Pls } & Ritonavir & $0.1 \pm 0.1$ & $63.92 \pm 43.03$ & 639 \\
\hline & Indinavir & $0.008 \pm 0.008$ & $>100$ & $>12500$ \\
\hline & Saquinavir & $0.004 \pm 0.007$ & $62.18 \pm 32.75$ & 15545 \\
\hline
\end{tabular}

NNRTIs: Non-nucleoside reverse transcriptase inhibitors; NRTIs: nucleoside RT inhibitors;

Pls: protease inhibitors

$\mathrm{EC}_{50}$ : Effective concentration of antiretroviral drug inhibited $50 \%$ virus replication.

$\mathrm{CC}_{50}$ : Cytotoxic concentration of antiretroviral drug showed cytotoxic effect in $50 \%$ of cells.

SI: selectivity index represents a ratio of $\mathrm{CC}_{50}$ to $E C_{50}$.

nized at 42 weeks pi. Blood, spleen and lymphoid tissues collected at necropsy revealed positive proviral DNA. In the non-DMPA-treated group, one macaque (03042) was euthanized at week 14 pi because of clinical complications with fatty liver, decreased liver function, weight loss, gastroenterocolitis, hind leg immobility, and frequent vocalizing. Severe loss of CD4+T cells and moderate level of proviral DNA were detected in peripheral blood, spleen, and lymphoid tissues of this macaque at euthanasia. The severity of disease syndrome of this macaque (03042) may have been only partially associated with RT-
SHIV infection. The other three macaques in this group did not develop AIDS-like illness before euthanized after week 24 pi.

\section{Discussion}

The purpose of this study was to thoroughly characterize an RT-SHIV virus and to determine whether this virus can be used to evaluate in vivo efficacy of potential HIV-1 preventive or therapeutic strategies especially NNRTI-based topical microbicides. We have shown that RT-SHIV replicates efficiently in both human and macaque PBMCs and
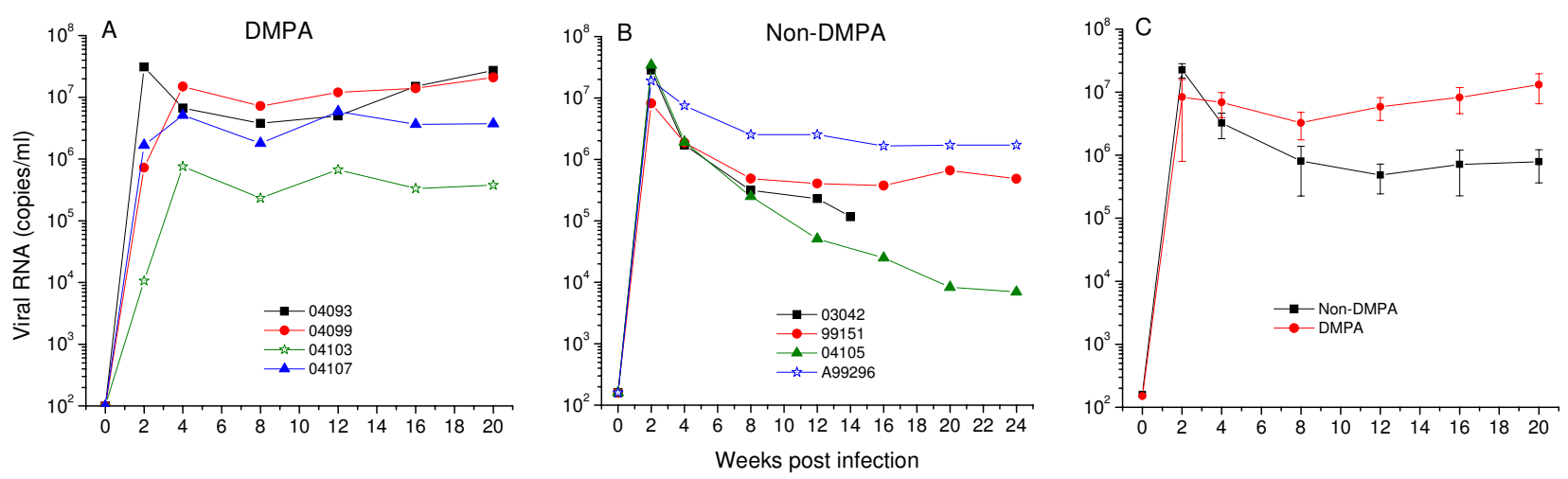

\section{Figure 3}

Plasma viral RNA levels in RT-SHIV infected macaques. Panel A shows viral RNA (copies $/ \mathrm{ml}$ ) from four macaques that were pretreated with a single $30 \mathrm{mg}$ dose of DMPA (depot medroxyprogesterone acetate, Depo Provera ${ }^{\circledR}$ ) for 30 days before intravaginal challenge with 500 or $1000 \mathrm{TCID}_{50}$ of RT-SHIV. Panel B shows viral RNA from four macaques that were not pretreated with DMPA before virus challenge. Panel $C$ represents the mean viral loads of four RT-SHIV infected macaques in the DMPA-treated or in the untreated group. In the non-DMPA group, viral RNA data from macaque 03042 were not available after 14 weeks post infection because this macaque was euthanized. The viral load of each plasma sample collected at various weeks pi (x-axis) was tested by standard branched chain DNA amplification assay. 
also in many different human $\mathrm{CD} 4+\mathrm{T}$ cell lines. This virus preferentially utilizes the CCR5 coreceptor for entry into the target cells. The in vitro efficacy and cytotoxicity evaluation of NNRTIs and other anti-HIV compounds against RT-SHIV infection were performed by using our virus stock which was originally derived from Louis Alexander [28]. As shown in Tables 1 and 2, this RT-SHIV was sensitive not only to three NNRTIs but also to NRTIs and PIs tested. The in vitro antiviral activity of NNRTIs in this study was comparable to other studies $[19,24]$ against the RT-SHIV virus which was originally derived from the same source [23]. In addition, another RT-SHIV ${ }_{\text {mne }}$ also showed a similar sensitivity to NNRTIs [26] as compared to this study. In short, our RT-SHIV stock is highly sensitive to
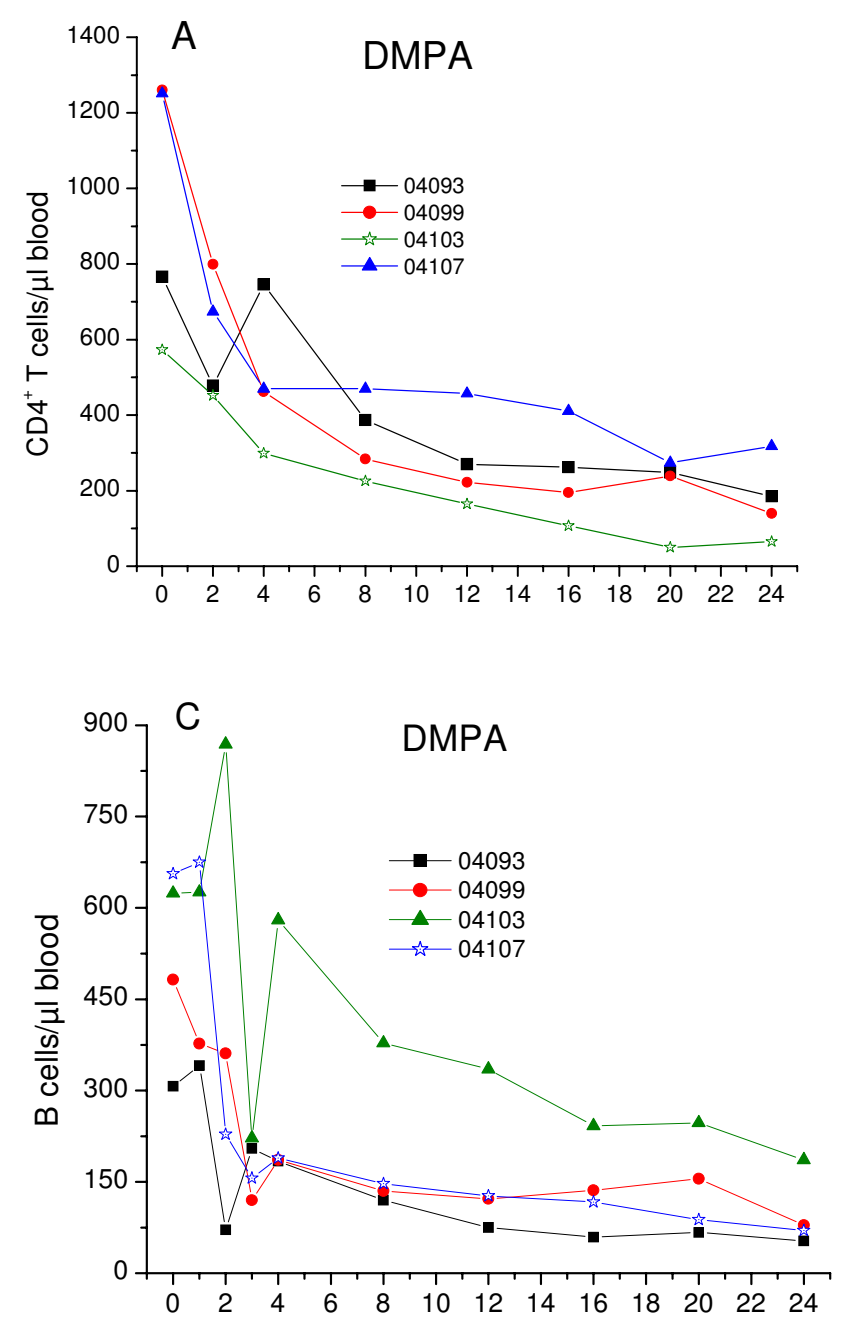

not only NNRTIs but also to other anti-HIV compounds (e.g., NRTIs and PIs) and thus, is suitable for in vitro efficacy evaluation of a wide variety of anti-HIV compounds.

To determine in vivo susceptibility of pigtail macaques we conducted a vaginal transmission study with RT-SHIV. All macaques became systemically infected with persistent high plasma viremia within two weeks after a single intravaginal inoculation of either 500 or $1,000 \mathrm{TCID}_{50}$ of virus regardless of DMPA pretreatment. All infected macaques show consistent $\mathrm{CD} 4+\mathrm{T}$ cell depletion and positive antiviral antibody response. There were no discernable differences in virus load and $\mathrm{CD} 4{ }^{+} \mathrm{T}$ cell depletion between DMPA- and non DMPA-treated macaques especially dur-
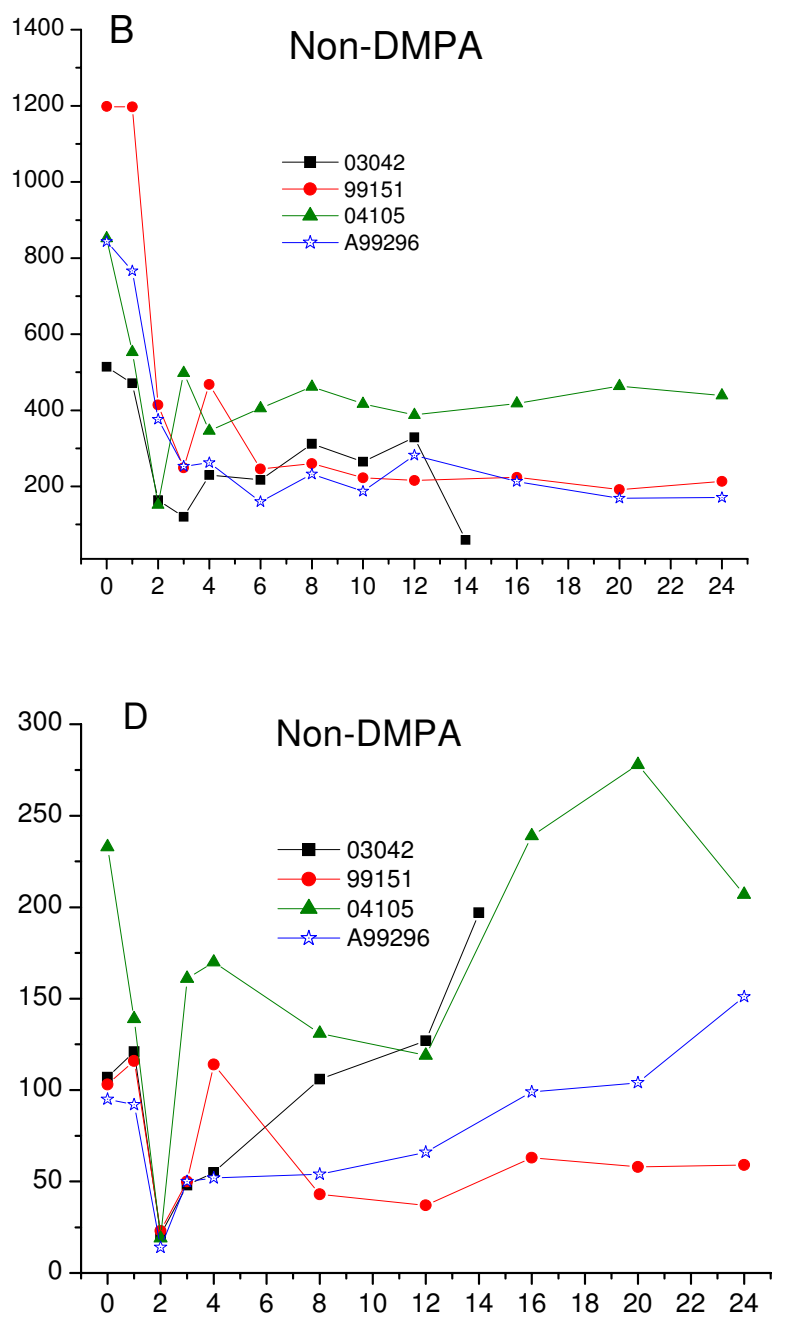

\section{Weeks post infection}

\section{Figure 4}

Changes of CD4 ${ }^{+}$T cell and B cell numbers in RT-SHIV infected macaques. A group of four macaques were either pretreated with a single dose of DMPA or untreated for 30 days prior to intravaginal virus challenge. Whole blood samples collected from macaques were analyzed at various weeks post infection ( $x$-axis) for absolute $C D 4^{+} T$ cells (panel $A$, DMPA; panel $B$, non-DMPA) and B cells (panel C, DMPA; panel D, non-DMPA) numbers that are shown at the $y$-axis. 
ing the acute phase of infection (weeks 1-4 pi). However, the average viremic level during the later stage (up to 20 weeks pi) was significantly higher in the DMPA-treated macaques (Figure 3A). Furthermore, the changes in B cell numbers, and the antiviral antibody responses were also significantly different between the two groups (Figures 4 and 5). Following the onset of modest increase during the acute infection (3-4 weeks pi) the B cell numbers in DMPA group continue to decrease until 24 weeks pi. While in contrast, the B cell numbers appear to increase in the non-DMPA group. Similarly, the antibody response was highly variable and overall lower in most of the DMPA macaques compare to the non-DMPA group. Immunosuppression has been noted previously in DMPA-treated macaques [38]. These investigators have also indicated low virus-specific IFN-gamma production in DMPA-treated macaques in response to SIV Gag. The immunosuppressive effect of DMPA on antiviral immune response may at least in part account for the increased viral burden and the diversity in antibody level seen in this study and by others [38]. Nevertheless, our findings with non-DMPA treated macaques indicate that this RTSHIV virus is highly infectious and readily transmissible through vaginal mucosa in pigtail macaques.

Most of the DMPA-treated animals developed AIDS-like disease compared to non-DMPA macaques. A couple of other laboratories have also reported intravaginal transmission of RT-SHIV in DMPA-treated rhesus macaques
[34,35]. In these studies the peak plasma viremia levels were similar to this current study, however, none of the infected macaques developed AIDS-like illness. These studies did not test RT-SHIV for mucosal susceptibility in non-DMPA treated macaques. In any case, regardless of the higher clinicopathologic severity in DMPA-treated macaques, the non-DMPA RT-SHIV model could be considered more relevant for evaluating microbicide or therapeutic agents especially since there will be no systemic effects on immune system as well as no unnatural thinning of vaginal mucosa caused by DMPA. Besides, single exposure of a moderate 500 or 1,000 TCID $_{50}$ dose of our RT-SHIV resulted in infection of all the exposed animals without DMPA treatment, and the peak viremia was similar to DMPA-treated animals observed in this and also in the other two studies [34,35]. Furthermore, careful mucosal infectivity dose titration may determine that even lower amount of virus could infect $100 \%$ pigtail macaques as shown in another study where a much lower dose of this virus infected all the intravaginally exposed cynomolgus macaques without DMPA treatment [36].

Nonhuman primates provide a surrogate animal model for HIV/AIDS study since they can not be directly infected by HIV. Moreover, they are also significantly less susceptible to chimeric SHIV (SIV with HIV-1 envelope); therefore, infection of high percentage of macaques through mucosal exposure with SHIV remains to be a challenge. To circumvent this low susceptibility issue, two macaque
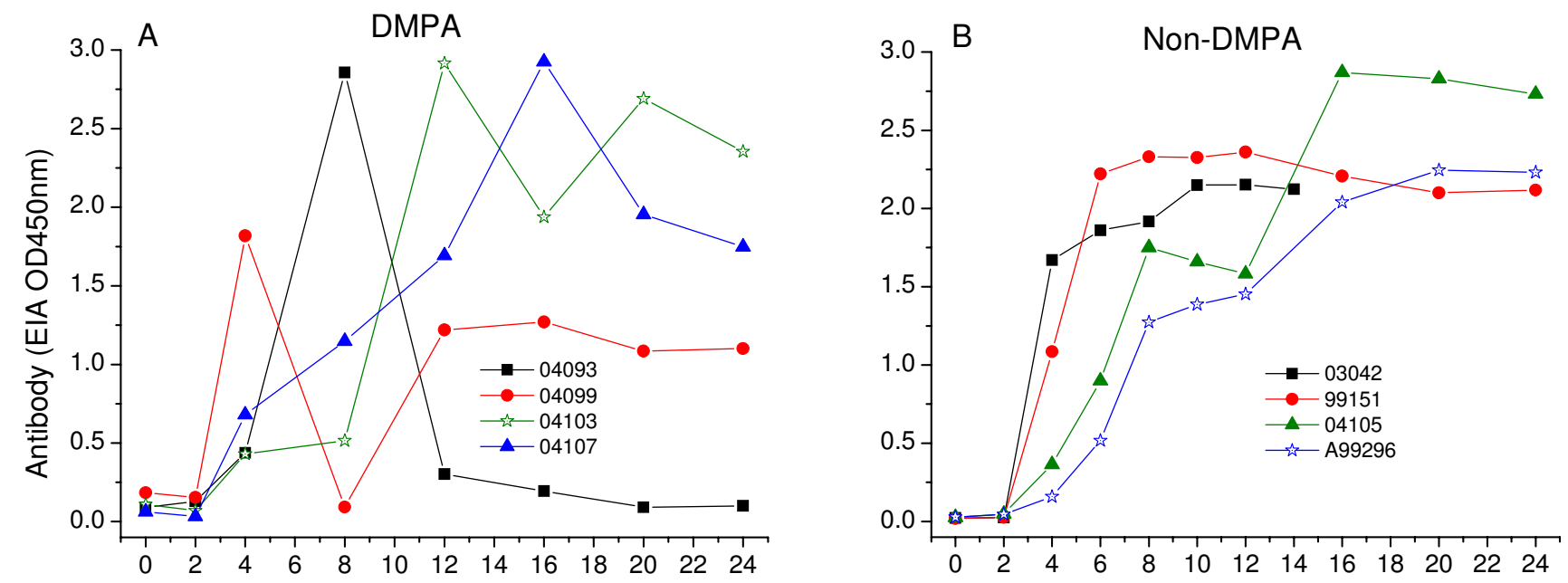

Weeks post infection

\section{Figure 5}

Antiviral antibody response in RT-SHIV infected macaques. A group of four macaques were either pretreated with a single dose of DMPA (Panel A) or untreated (Panel B) for 30 days prior to intravaginal virus challenge. Serum samples collected from each macaque at different weeks post infection ( $x$-axis) were tested for anti-SIV antibodies by an enzyme immunoassay. The OD450 $\mathrm{nm}$ value of each serum shown at the $y$-axis is the mean of two different values. 
models; single-dose DMPA and repeated low-dose (nonDMPA) infection models, have been investigated $[11,12,42]$. DMPA causes non-physiological thinning of vaginal epithelia to enhance virus penetration through mucosa. Also, evidence suggests that DMPA may have global effects on immune system as mentioned earlier [38]. On the other hand, repeated low-dose model may achieve a high rate of macaque infection through large number of mucosal exposures; however, it is proved to be highly labor intensive, expensive and technically challenging. Overall, given the drawbacks of the two existing models, intravaginal susceptibility of $100 \%$ macaques by single dose of our RT-SHIV without DMPA-treatment (observed in this study) may prove to be a model of clear advantages over the both single-dose DMPA and repeated low-dose (non-DMPA) macaque models.

\section{Conclusion}

In vitro studies confirmed that this RT-SHIV stock exhibits the critical characteristics of high replication capability in PBMCs from both humans and macaques, and the preferential use of CCR5-coreceptor for the viral entry into target cells. In vitro antiviral assays also revealed that RTSHIV is sensitive to HIV-specific NNRTIs and other major classes of anti-HIV drugs. More importantly, in vivo study demonstrated that this virus is highly infectious and readily transmissible through vaginal mucosa of macaques, without pretreatment with DMPA (Depo Provera ${ }^{\circledR}$ ). Thus, this RT-SHIV macaque model may have advantages over the existing models and could be suitable for preclinical efficacy evaluation of NNRTI-based microbicides or other prevention strategies against sexual transmission of HIV-1.

\section{Materials and methods Viruses}

The parental chimeric RT-SHIV virus (RT/SHIV/TC) kindly provided by Louis Alexander [28] was initially propagated in CEMx174 cells and tested in several in vitro studies using human lymphoid cell lines and PBMCs. To increase infectivity, this virus was serially passaged in CEMx174 cells and PBMCs from both healthy humans and Asian-origin macaques. Since this RT-SHIV replicates better in CEMx174 cells than in phytohemagglutinin (PHA)-stimulated PBMCs (Figure 1A,B), a large stock of actively propagating viruses (named RT-SHIV) was prepared in CEMx174 cells. The infectivity titer of this virus stock was also determined in CEMx174 cells

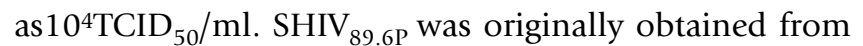
Keith Reimann [43] and propagated in PHA-stimulated PBMC from naïve pigtail macaques. HIV-1 $1_{\mathrm{Lai}}, \mathrm{HIV}-1_{\mathrm{BaL}}$

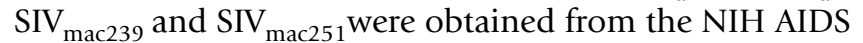
Research and Reference Reagent Program. SIV strains were also propagated and titrated in CEMx174 cells.

\section{Cells and reagents}

Human cell lines (CEMx174, MT-2, MT-4, PM-1, MOLT4CCR5) and all anti-HIV compounds (Efavirenz, Nevirapine, UC781, AZT, 3TC, D4T, FTC, Tenofovir, Ritonavir, Saquinavir, TAK-779, and AMD-3100) were obtained through the NIH AIDS Research and Reference Reagent Program. Cell lines were maintained in complete HEPES-buffered RPMI-1640 medium containing 10\% heat-inactivated FBS (fetal bovine serum) (GEMINI Bioproducts, Woodland, CA), $2 \mathrm{mM}$ L-glutamine and $50 \mu \mathrm{g} /$ $\mathrm{ml}$ penicillin/streptomycin (GIBCO, Grand Island, NY). PBMCs were obtained from healthy donors of humans or macaques (M. nemestrina and M. fascicularis). All PBMCs were isolated from EDTA-treated blood of donors by Ficoll gradient centrifugation and cultured for $48 \mathrm{~h}$ in RPMI medium containing rIL2 $(20 \mathrm{ng} / \mathrm{ml})$ and PHA $(2.5$ $\mu \mathrm{g} / \mathrm{ml})$ at a density of $2 \times 10^{6}$ cells $/ \mathrm{ml}$. The stimulated PBMCs were washed free of PHA and cultured in complete RPMI1640 medium containing rIL2 (20 ng/ml), 10\% FBS, and $50 \mu \mathrm{g} / \mathrm{ml}$ penicillin/streptomycin.

\section{In vitro characterization of RT-SHIV}

To assess virus infectivity, PHA-stimulated PBMCs (humans or macaques) or CEMx174 cells were incubated for 4 hours with RT-SHIV at a multiplicity of infection (moi) of 0.01, washed once, and then cultured for 7-10 days. The infectivity of all other viruses (SIV, SHIV, or HIV-1) was tested as controls following the same procedure. To determine coreceptor usage, triplicate wells containing PHA-activated human or macaque PBMC $\left(10^{6} \mathrm{ml}\right)$ were pretreated with or without the CCR5 antagonist TAK$779(10 \mu \mathrm{M})$ or the CXCR4 antagonist AMD-3100 (1,000 $\mathrm{ng} / \mathrm{ml}$ ) for 2 hours at $37^{\circ} \mathrm{C}$ incubation before adding to RT-SHIV. Cells were then incubated with RT-SHIV for another four hours, washed to remove unattached virus, and cultured for 7-10 days. Virus replication in cell cultures was monitored by cytopathic effect (syncytium formation)) and by measuring either SIV p27 or HIV-1 p24 antigen in the culture supernatants using ELISA (ZeptoMetrix Corporation, Buffalo, NY).

\section{In vitro efficacy assays for NNRTIs and other anti-HIV compounds}

To determine in vitro efficacy of NNRTIs or other drugs, target cells (MT-4, CEMx174 and MT-2) were added into 96 -well plates $\left(1 \times 10^{4}\right.$ cells/well $)$ in duplicate and treated with or without various concentrations of drugs for two hours at $37^{\circ} \mathrm{C}$ before incubating with different viruses (HIV-1, SIV and SHIV ${ }_{89.6 \mathrm{P}}$ ) for 6-7 days. Virus replication was monitored by measuring either SIV p27 or HIV-1 p24 antigen in the culture supernatants by ELISA. This procedure was used to determine the $50 \%$ effective concentration $\left(\mathrm{EC}_{50}\right)$ for each drug [44]. 


\section{Drug cytotoxicity assays}

To determine the cytotoxic effects, actively growing target cells were similarly incubated with increasing concentration of each drug for 6-7 days without adding the virus and then monitored the cell viability. Cytotoxicity was evaluated by the standard MTT [3-(4,5-dimethylthiazol-2yl)-2,5-diphenyltetrazolium bromide] assay as described previously [45]. This assay was used to determine the $50 \%$ cytotoxic concentration $\left(\mathrm{CC}_{50}\right)$ for each drug [44]. All experiments were run in duplicate.

\section{Macaques and clinical procedures}

Eight naïve pigtail macaques (M. nemestrina) were housed at the Washington National Primate Research Center in compliance with its Guide for the Care and Use of Laboratory Animals. All macaques were confirmed to be serologically negative for simian type D retrovirus, SIV, and simian Tcell lymphotropic virus (STLV) prior to infection. One group of four macaques was pretreated with DMPA (depot medroxyprogesterone acetate, Depo Provera ${ }^{\circledR}$; a single dose of $30 \mathrm{mg}$ ) for 30 days prior to virus challenge to minimize animal susceptibility variation by synchronizing their reproductive cycles. Another group of four macaques were not pretreated with DMPA prior to virus challenge. Two macaques in each group were inoculated intravaginally with 500 TCID $_{50}$ of RT-SHIV; the remaining two macaques in each group received $1,000 \mathrm{TCID}_{50}$ as previously described $[13,14]$. Briefly, $0.5 \mathrm{ml}$ of virus preparation was atraumatically introduced to the vaginal mucosa using a stainless steel animal feeding tube. All macaques were kept in a knee-chest position for at least 15 minutes to maintain exposure of the virus inoculum to the cervicovaginal mucosa. To monitor systemic virus infection, blood samples were collected from each macaque at weekly during the first month, then every two weeks for two months and then monthly for next three months pi. All procedures for animal handlings were performed under ketamine $(10 \mathrm{mg} / \mathrm{kg})$ anesthesia. All macaques were inspected daily for general health condition and any signs or symptoms of illness. Other clinical assessments included periodic blood samples for CBC (complete blood counts), serum biochemistry tests, and clinical laboratory diagnoses of suspected causes, if indicated.

\section{Lymphocyte subset analysis}

To quantify the absolute number of peripheral blood CD4 ${ }^{+} \mathrm{T}$ cells, CD8 ${ }^{+} \mathrm{T}$ cells and $\mathrm{B}$ cells in the infected macaques, lymphocyte phenotyping was performed on EDTA blood samples stained with mouse anti-human monoclonal antibodies that reacted with macaque lymphocytes. Lymphocyte subsets were analyzed with a FACSCalibur flow cytometer and Cellquest software (Becton Dickinson). $\mathrm{CD}^{+}$and $\mathrm{CD}^{+} \mathrm{T}$ lymphocytes were defined as $\mathrm{CD}^{+}{ }^{+} \mathrm{CD} 4{ }^{+}$and $\mathrm{CD}^{+}{ }^{+} \mathrm{CD} 8{ }^{+}$, respectively and $\mathrm{B}$ lymphocytes as CD3-CD20+.

\section{Virus isolation from RT-SHIV infected macaques}

The frequency of infected cells in blood was estimated by quantitative coculture of PHA-stimulated PBMC with uninfected CEMx174 cells. RT-SHIV from infected cells readily infects CEMx174 cells and induces marked syncytia in the culture. Infection was monitored by microscopic examination for syncytium formation and by measuring SIV gag protein in the culture supernatants using SIV p27 antigen capture ELISA (ZeptoMetrix Corp., Buffalo, NY).

\section{Detection of plasma virus RNA}

The level of plasma viremia was quantified by the standard branched chain DNA (bDNA) amplification assay (Siemens Medical Solutions Diagnostics, Berkeley, CA). The limit of detection of viral RNA was 125 copies per milliliter of plasma.

\section{Detection of proviral DNA in PBMC}

Genomic DNA was extracted from $1 \times 10^{6}$ PBMC using the Qiagen DNA Blood Kit (QIAamp DNA Blood Mini Kit, Cat \# 51106). SIVmac239 gag-specific primers were used to amplify virus DNA by PCR as described previously $[13,14,46]$.

\section{Antiviral antibody assay}

Viral antibody titer was assayed by the HIV-2 EIA kit (BioRad Laboratories, Redmond, WA), taking advantage of the strong cross reactivity of SIV antibodies to HIV-2 antigen. Plasma samples from all time points were tested for the presence of RT-SHIV antibodies following manufacturer's protocol.

\section{Competing interests}

The authors declare that they have no competing interests.

\section{Authors' contributions}

YJ carried out the experiments, performed data analysis and wrote the initial draft of the manuscript; BT performed efficacy assays for NNRTIs and other anti-HIV drugs and data interpretation; MBA helped with data interpretation and manuscript review; PE helped with laboratory experiments and data analysis. MS and JSC both supported the study plan for the development of an intravaginal infection model with RT-SHIV, helped with discussion on the study progress and review of manuscript. CCT was responsible for the overall experimental design, implementation of the project, data interpretation and manuscript writing.

\section{Acknowledgements}

We thank the veterinary and animal husbandry staff at the Washington National Primate Research Center for excellent care of animals. We thank Dr. Louis Alexander at Yale University for providing the original RT/SHIV/ TC stock and Dr. Kailash Gupta for his consultation on the study plan and discussion of the study progress. We also thank the NIH AIDS Research and Reference Reagent Program for providing the human cell lines and 
antiretroviral drugs/compounds. This study was supported by NIH-NIAID contract NOI-Al-I5450 and NIH grant RR-00I66.

\section{References}

I. Cohen MS, Gay C, Kashuba ADM, Blower S, Paxton L: Narrative Review: Antiretroviral therapy to prevent the sexual transmission of HIV-I. Ann Intern Med 2007, I46:59I-60I.

2. Klasse PJ, Shattock R, Moore JP: Antiretroviral drug-based microbicides to prevent HIV-I sexual transmission. Ann Rev Med 2008, 59:455-47I.

3. Lederman MM, Offord RE, Hartley $O$ : Microbicides and other topical strategies to prevent vaginal transmission of HIV. Nature Review Immunology 2006, 6:371-382.

4. Stone A, Jiang S: Microbicides: stopping HIV at the gate. Lancet 2006, 368:43I-433.

5. Shattock RJ, Moore JP: Inhibiting sexual transmission of HIV-I infection. Nat Rev Microbiol 2003, I:25-34.

6. Trager RS: Microbicides: Raising New Barriers HIV Infection. Science 2003, 299:39.

7. Turpin JA: Considerations and development of topical microbicides to inhibit the sexual transmission of HIV. Expert Opin Investig Drugs 2002, I I:1077-1097.

8. Moench TR, Chipato T, Nancy S, Padian NS: Preventing disease by protecting the cervix: the unexplored promise of internal vaginal barrier devices. AIDS 200I, I5:I595-I602.

9. McCormack S, Hayes R, Lacey CJ, Johnson AM: Science, medicine, and the future: Microbicides in HIV prevention. BMJ 200I, 322:410-413.

10. Pauwels R, DeClercq E: Development of vaginal microbicides for the prevention of heterosexual transmission of HIV. J Acquir Immune Defic Syndr Hum Retrovirol 1996, I I :2 I I-22 I.

II. Veazey RS, Klasse PJ, Schader SM, Hu Q, Ketas TJ, Lu M, Marx PA, Dufour J, Colonno RJ, Shattock RJ, Springer MS, Moore JP: Protection of macaques from vaginal SHIV challenge by vaginally delivered inhibitors of virus-cell fusion. Nature 2005, 438:99-102.

12. Lederman MM, Veazey RS, Offord R, Mosier DE, Dufour J, Mefford M, Piatak M Jr, Lifson JD, Salkowitz JR, Rodriguez B, Blauvelt A, Hartley O: Prevention of vaginal SHIV transmission in rhesus macaques through inhibition of CCR5. Science 2004, 306:485-487.

13. Tsai C-C, Emau P, Jiang YH, Agy MB, Shattock RJ, Schmidt A, Morton WR, Gustafson KR, Boyd MR: Cyanovirin-N inhibits AIDS virus infections in vaginal transmission models. AIDS Res Hum Retroviruses 2004, 20: II-18.

14. Jiang YH, Emau P, Cairns JS, Flanary L, Morton WR, McCarthy TD, Tsai C-C: SPL70 3 gel as a topical microbicide for prevention of vaginal transmission of SHIV89.6P in macaques. AIDS Res Hum Retroviruses 2005, 2 I:207-2 I 3.

15. D'Cruz OJ, Uckun FM: Dawn of non-nucleoside inhibitor-based anti-HIV microbicides. J Antimicrob Chemother 2006, 57:4 I I-423.

16. Patton DL, Sweeney YT, Balkus JE, Rohan LC, Moncla BJ, Parniak MA, Hillier SL: Preclinical safety assessments of UC78I antihuman immunodeficiency virus topical microbicide formulations. Antimicrob Agents Chemother 2007, 5 I:I608-16I5.

17. Pani A, Musiu C, Loi AG, Mai A, Loddo R, La Colla P, Marongiu ME: DABOs as candidates to prevent mucosal HIV transmission. Antivir Chem Chemother 2001, I 2:51-59.

18. Barnard J, Borkow G, Parniak MA: The thiocarboxanilide nonnucleoside UC78 I is a tight-binding inhibitor of HIV-I reverse transcriptase. Biochemistry 1997, 36:7786-7792.

19. Balzarini J, Naesens L, Verbeken E, Laga M, Van Damme L, Parniak M, Van Mellaert L, Anne J, De Clercq E: Preclinical studies on thiocarboxanilide UC-78I as a virucidal agent. AIDS 1998, I 2: I 129-I I 38 .

20. Zussman A, Lara L, Lara HH, Bentwich Z, Borkow G: Blocking of cell-free and cell-associated HIV-I transmission through human cervix organ culture with UC78I. AIDS 2003, | 7:653-661.

21. Fletcher P, Kiselyeva Y, Wallace G, Romano J, Griffin G, Margolis L, Shattock R: The nonnucleoside reverse transcriptase inhibitor UC-78 I inhibits human immunodeficiency virus type I infection of human cervical tissue and dissemination by migratory cells. J Virol 2005, 79: I I I79-I I I86.
22. Van Herrewege $Y$, Michiels J, Van Roey J, Fransen K, Kestens L, Balzarini J, Lewi P, Vanham G, Janssen P: In vitro evaluation of nonnucleoside reverse transcriptase inhibitors UC-78I and TMCI 20-RI4768 I as human immunodeficiency virus microbicides. Antimicrob Agents Chemother 2004, 48:337-339.

23. Uberla K, Stahl-Hennig C, Bottiger D, Matz-Rensing K, Kaup FJ, Li J, Haseltine WA, Fleckenstein B, Hunsmann G, Oberg B, Joseph Sodroski: Animal model for the therapy of acquired immunodeficiency syndrome with reverse transcriptase inhibitors. Proc Natl Acad Sci USA 1995, 2:8210-82।4.

24. Balzarini J, DeClercq E, Uberla K: SIV/HIV-I hybrid virus expressing the reverse transcriptase gene of HIV-I remains sensitive to HIV-I specific reverse transcriptase inhibitors after passage in rhesus macaques. J Acquir Immune Defic Syndr Hum Retrovirol 1997, I 5: I-4.

25. Zuber B, Bottiger D, Benthin R, ten Haaft P, Heeney J, Wahren B, Oberg $B$ : An in vivo model for HIV resistance development. AIDS Res Hum Retroviruses 2001, I 7:631-635.

26. Ambrose Z, Boltz V, Palmer S, Coffin JM, Hughes SH, Kewalramani $\mathrm{VN}$ : In vitro characterization of a simian immunodeficiency virus-human immunodeficiency virus (HIV) chimera expressing HIV type I reverse transcriptase to study antiviral resistance in pigtail macaques. J Virol 2004, 78: |3553-|356 I.

27. Akiyama H, Ido E, Akahata W, Kuwata T, Miura T, Hayami M: Construction and in vivo infection of a new simian/human immunodeficiency virus chimera containing the reverse transcriptase gene and the 3 ' half of the genomic region of human immunodeficiency virus type I. J Gen Virol 2003, 84: I663-1669.

28. Soderberg K, Denekamp L, Nikiforow S, Sautter K, Desrosiers RC, Alexander LA: Nucleotide substitution in the tRNA(Lys) primer binding site dramatically increases replication of recombinant simian immunodeficiency virus containing a human immunodeficiency virus type I reverse transcriptase. J Virol 2002, 76:5803-5806.

29. Ambrose Z, Palmer S, Boltz VF, Kearney M, Larsen K, Polacino P, Flanary L, Oswald K, Piatak M Jr, Smedley J, Shao W, Bischofberger N, Maldarelli F, Kimata JT, Mellors JW, Hu SL, Coffin JM, Lifson JD, Kewalramani VN: Suppression of Viremia and Evolution of HIV-I Drug Resistance in a Macaque Model for Antiretroviral Therapy. J Virol 2007, 8 I: I 2145-12 I55.

30. Mori K, Yasutomi Y, Sawada S, Villinger F, Sugama K, Rosenwith B, Heeney JL, Uberla K, Yamazaki S, Ansari AA, Rubsamen-Waigmann $\mathrm{H}$ : Suppression of acute viremia by short-term postexposure prophylaxis of simian/human immunodeficiency virus SHIVRT-infected monkeys with a novel reverse transcriptase inhibitor (GW420867) allows for development of potent antiviral immune responses resulting in efficient containment of infection. J Virol 2000, 74:5747-5753.

31. North TW, Van Rompay KK, Higgins J, Matthews TB, Wadford DA, Pedersen NC, Schinazi RF: Suppression of virus load by highly active antiretroviral therapy in rhesus macaques infected with a recombinant simian immunodeficiency virus containing reverse transcriptase from human immunodeficiency virus type I. J Virol 2005, 79:7349-7354.

32. Hofman MJ, Higgins J, Matthews TB, Pedersen NC, Tan C, Schinazi RF, North TW: Efavirenz therapy in rhesus macaques infected with a chimera of simian immunodeficiency virus containing reverse transcriptase from human immunodeficiency virus type I. Antimicrob Agents Chemother 2004, 48:3483-3490.

33. Rosenwirth B, ten Haaft P, Bogers WM, Nieuwenhuis IG, Niphuis H, Kuhn EM, Bischofberger N, Heeney JL, Uberla K: Antiretroviral therapy during primary immunodeficiency virus infection can induce persistent suppression of virus load and protection from heterologous challenge in rhesus macaques. J Virol 2000, 74: I704-171I.

34. Turville SG, Aravantinou M, Miller T, Kenney J, Teitelbaum A, Hu L, Chudolij A, Zydowsky TM, Piatak M Jr, Bess JW Jr, Lifson JD, Blanchard J, Gettie A, Robbiani M: Efficacy of Carraguard-based microbicides in vivo despite variable in vitro activity. PLoS ONE 2008, 3: I- I4.

35. Pal R, Nuttall J, Galmin L, Weiss D, Chung HK, Romano J: Characterization of vaginal transmission of a simian human immunodeficiency virus (SHIV) encoding the reverse transcriptase gene from HIV-I in Chinese rhesus macaques. Virology 2009, 386:102-108. 
36. Jiang y, Tian B, Agy MB, Saifuddin M, Tsai C-C: Macaca fascicularis are highly susceptible to an RT-SHIV following intravaginal inoculation: a new model for microbicide evaluation. J Med Primatol 2009, 38(Suppl. I):39-46.

37. Marx PA, Spira Al, Gettie A, Dailey PJ, Veazey RS, Lackner AA, Mahoney CJ, Miller CJ, Claypool LE, Ho DD, Alexander NJ: Progesterone implants enhance SIV vaginal transmission and early virus load. Nat Med 1996, 2:1084-1089.

38. Trunova N, Tsai L, Tung S, Schneider E, Harouse J, Gettie A, Simon V, Blanchard J, Cheng-Mayer C: Progestin-based contraceptive suppresses cellular immune responses in SHIV-infected rhesus macaques. Virology 2006, 352:169-177.

39. Dragic T, Trkola A, Thompson DA, Cormier EG, Kajumo FA, Maxwell E, Lin SW, Ying W, Smith SO, Sakmar TP, Moore JP: A binding pocket for a small molecule inhibitor of HIV-I entry within the transmembrane helices of CCR5. Proc Natl Acad Sci USA 2000, 97:5639-5644.

40. Hendrix CW, Flexner C, MacFarland RT, Giandomenico C, Fuchs EJ, Redpath E, Bridger G, Henson GW: Pharmacokinetics and safety of AMD- a novel antagonist of the CXCR-4 chemokine receptor, in human volunteers. Antimicrob Agents Chemother 3100, 44:1667-1673.

4I. Klasse PJ, Rosenkilde MM, Signoret N, Pelchen-Matthews A, Schwartz TW, Marsh M: CD4-Chemokine Receptor Hybrids in Human Immunodeficiency Virus Type I Infection. J Virol 1999, 73:7453-7466.

42. Tsai L, Trunova N, Gettie A, Mohri H, Bohm R, Saifuddin M, ChengMayer C: Efficient repeated low-dose intravaginal infection with X4 and R5 SHIVs in rhesus macaque: implications for HIV-I transmission in humans. Virology 2007, 362:207-216.

43. Reimann KA, Li JT, Veazey R, Halloran M, Park IW, Karlsson GB, Sodroski J, Letvin NL: A chimeric simian/human immunodeficiency virus expressing a primary patient human immunodeficiency virus type I isolate env causes an AIDS-like disease after in vivo passage in rhesus monkeys. J Virol 1996, 70:6922-6928.

44. Emau P, Tian B, O"keefe BR, Mori T, MacMahon JB, Palmer KE, Jiang Y, Bekele G, Tsai CC: Griffithsin, a potent HIV entry inhibitor, is an excellent candidate for anti-HIV microbicide. J Med Primatol 2007, 36:244-253.

45. Mosmann T: Rapid colorimetric assay for cellular growth and survival: Application to proliferation and cytotoxicity assays. J Immunol Methods 1983, 65:55-63.

46. Watson A, Ranchalis J, Travis B, McClure J, Sutton W, Johnson PR, Hu SL, Haigwood NL: Plasma viremia in macaques infected with simian immunodeficiency virus: plasma viral load early in infection predicts survival. J Virol 1997, 7 I:284-290.

Publish with Bio Med Central and every scientist can read your work free of charge

"BioMed Central will be the most significant development for disseminating the results of biomedical research in our lifetime. "

Sir Paul Nurse, Cancer Research UK

Your research papers will be:

- available free of charge to the entire biomedical community

- peer reviewed and published immediately upon acceptance

- cited in PubMed and archived on PubMed Central

- yours - you keep the copyright

Submit your manuscript here:

http://www.biomedcentral.com/info/publishing_adv.asp
BioMedcentral 